\title{
1. Introduction: what is the New Economy?
}

\section{Dennis W. Jansen}

\section{INTRODUCTION}

What is the New Economy? Is it new? What makes it new? What are the implications of the New Economy for antitrust and regulation policy, and for macroeconomic policy? These are some of the questions that were examined by a gathering of eminent scholars at a conference at Texas A\&M University in April 2002. This conference, hosted by the George Bush School of Government and Public Service with the support of the Department of Economics, is part of an annual conference series on economics and public policy.

The phrase 'the New Economy' means different things to different people. In the popular press it is often used to refer to the information economy, to the high-tech economy, to the technology revolution, or to the many-faceted impact of the explosive growth of the World Wide Web. The New Economy has been used to signify the increased productivity brought forth by various technological innovations, or to refer to the long-lasting expansion from 1991 through 2000, or even to the long-lasting stock market boom from 1987 through 2000.

In addition to sometimes confusing or confused definitions, there are clear excesses in the hype that has sometimes accompanied the phrase 'New Economy'. When popular prognosticators were saying that the New Economy would be immune to business cycles and recessions, economists would cringe, wondering when the recession would hit to prove such claims false. When stock market oracles were predicting DOW 30000 and the like, economists concerned with the already-high PE ratios would wonder when the bear market would begin, and how bad it would be for stockholders.

However, despite these excesses, it is the opinion of many respected researchers and academics that there is something new about the New Economy. It is not quite so new or revolutionary as journalists wanted us to believe, or needed to hype in order to generate interest from their readers. 
But it is safe to say that the economy has changed in the last decade or so, and that these changes are of sufficient importance to deserve the title 'New Economy'.

In organizing this conference I wanted to provide an overview of various aspects of the New Economy. The conference began with a look at what I regard as the defining feature of the New Economy, the productivity growth brought on by the information technology revolution. Academic economists have debated how to measure this increase in productivity, its causes, and even its existence. Two papers addressed this issue, the first presented by Dale Jorgenson of Harvard University, and the second by Jack Triplett of the Brookings Institution.

\section{PRODUCTIVITY AND THE NEW ECONOMY}

Dale Jorgenson, with coauthors Mun S. Ho and Kevin J. Stiroh, led off the conference with their paper titled 'Projecting productivity growth: Lessons from the US growth resurgence'. Economists have long known that the growth rate of average labor productivity declined in the mid-1970s, and considerable research effort has been devoted to explaining this decline. Jorgenson et al. measure productivity growth as 2.97 per cent per year over 1959-73, declining by over one-half, to 1.44 per cent per year, for 1974-95. This decline has long been a concern, as a decline in the growth rate of labor productivity leads to concerns regarding the future growth rate of living standards. Jorgenson et al. find that this decline in productivity growth is due to a decline in the growth of capital services per worker (capital deepening), a decline in the growth of labor quality, and a decline in growth of what economists call total factor productivity. The increase in average labor productivity growth since 1995, a growth rate of 2.36 per cent per year over 1995-2000, is thus regarded as a welcome reversal of the decline in the mid1970s. The source of this increased productivity growth is capital deepening and increased total factor productivity growth. Jorgenson et al. estimate that growth due to IT capital deepening has doubled from 1959-73 to 1974-94, and doubled again from 1995-2000. They estimate that TFP growth due to IT-related factors has also experienced two doubles from the 1959-73 period to the 1995-2000 period. These IT-related factors account for an additional 0.71 per cent annual productivity growth from 1974-94 to 1995-2000. For comparison, the total additional annual productivity growth over these periods is estimated as 0.92 per cent. Thus Jorgenson et al. estimate that the IT 'revolution' is responsible for the lion's share of the additional labor productivity growth experienced by the US economy over the last half of the 1990s. 
Jorgenson then turns to providing an estimate of future US productivity growth. This is an important issue for long-term economic projections including debt and deficit projections as well as Social Security and Medicare projections. It is also a difficult task, fraught with uncertainty.

Difficulties in estimating productivity growth and the related concept of potential GDP growth have been with us since the concept of potential GDP was first introduced, so the recent change in productivity growth is not unprecedented. In fact, the decline in labor productivity by roughly half in the mid-1970s not only led to research seeking an explanation but also caused consternation among policy-makers. The failure of monetary policy in the later half of the 1970s has been blamed in some quarters on the Federal Reserve System's slow realization and slow response to the decline in productivity growth. Thus the experience of rising labor productivity growth rates in the mid-1990s is just the flip side of the experience two decades earlier.

In Jorgenson et al.'s base-case projections of trend labor productivity growth for the decade $2000-10$ is 2.21 per cent per year, with corresponding output growth of 3.31 per cent per year. Estimates of labor productivity growth range from the pessimistic projection of 1.33 per cent per year basically the growth rate over 1973-94 - to the optimistic projection of 2.92 per cent per year. The output growth rate projection ranges from the pessimistic 2.43 per cent per year to the optimistic 4.02 per cent per year. For comparison, this is below the 1995-2000 average of 4.60 per cent annual growth in output, due to slower projected growth in hours worked.

The productivity and output growth rate projections have large ranges of values due to uncertainties regarding future technical change in the production of information technology equipment and related investment patterns.

Following the presentation by Jorgenson, Jack E. Triplett presented his joint paper with Barry P. Bosworth, "Baumol's disease" has been cured: IT and multifactor productivity in US services industries'. This paper addressed two issues from the productivity literature. First, what are the contributions of information technology (IT) and multifactor productivity (MFP) to the extraordinary performance of the US economy in the last half of the 1990s. That extraordinary performance included historically low unemployment rates without accompanying inflation, and labor productivity growth doubling after 1995 from its lackluster performance over the prior two decades. These developments are often taken as evidence of the New Economy, especially if they can be related to increased IT use.

The second research issue concerns what is called 'Baumol's disease', the idea that the very nature of service industries make them less likely to exhibit productivity growth. The argument is that service industries are laborintensive, and that it is inherently difficult to substitute capital for labor in service industries. The evidence seems to support this conclusion, as service 
industries have long exhibited low growth rates of labor productivity compared to, say, manufacturing industries.

Triplett and Bosworth examined whether IT impacts on productivity by looking at those parts of the economy that are heavy IT users. They identify service industries as the most intensive IT industries, and find a substantial contribution of IT to growth of productivity in service industries. They do not, however, find a greater impact of IT on the service industries after 1995. Instead, they find that MFP in the service industries grew more rapidly after 1995 .

Triplett and Bosworth then look at the various service industries to estimate labor productivity growth over recent years. They estimate productivity growth for 27 two-digit services industries and find that in recent years labor productivity in these industries has grown as fast as in the rest of the economy. Further, they find that the major contributor to labor productivity growth in the service industries was an acceleration in multifactor productivity. Thus the authors conclude that, in the New Economy, Baumol's disease has been cured.

\section{MACROECONOMIC IMPLICATIONS OF AND FOR THE NEW ECONOMY}

An important question is what if anything will be the effect of the New Economy on macroeconomic policy, and the implications of the New Economy for macroeconomics in general. Stephen Cecchetti presented 'The New Economy and the challenges for macroeconomic policy', an overview of the relation between advances in information and communication technology and macroeconomic policy-making. Cecchetti argues that certain features of the New Economy make fiscal policy less attractive for stabilization purposes while at the same time increasing the difficulties facing monetary policy-makers. He points out both short-term and longer-term difficulties. Short-run difficulties include the problems of estimating potential output, especially when the productivity trend is shifting. Part of the reason for the great interest in measuring labor productivity growth rates and predicting future labor productivity growth rates is the importance of distinguishing permanent from transitory changes in growth rates when making macroeconomic policy. Many debates over monetary policy at the Federal Reserve System in the past decade turned on issues of deciding if the observed productivity growth rates were signaling a permanent or a transitory shift in growth rates.

Cecchetti points to three changes to the structural underpinnings of the economy that are likely to have lasting effects. These are (1) a reduction in 
the level of inventories, as production is tied more closely to demand and responds more quickly to changes in demand; (2) the rising proportion of temporary workers, a phenomenon that gives companies the ability to respond more quickly to business conditions by adjusting the size of their workforce; and (3) innovations in finance that provide companies and consumers better access to resources even when times are tough. The first two features, which increase the speed at which output adjusts to changing demand conditions, have the potential for making it more important for policy-makers to themselves respond more quickly to business cycle conditions. That, combined with the difficulty of distinguishing permanent from transitory shocks, has the potential to make macroeconomic policy-making more difficult in the New Economy.

The evolution of the financial system poses a particularly difficult challenge for central bankers. Since monetary policy acts initially through its impact on the balance sheets of financial firms, the explosion of asset-backed securities has likely changed the mechanism by which interest rate changes affect the real economy. As more borrowers have access to primary capital markets, and fewer need banks, it may become more difficult for the actions of central bankers to alter the future path of output and inflation.

The first three papers presented a general overview of The New Economy, including an overview of the productivity increase and how it can be linked to information technology, and an overview of the implications of The New Economy for macroeconomic policy making. The next four papers dealt with more specific issues of the New Economy. Nicholas Economides of New York University addressed the special features of network industries and the implications for antitrust policy. John Morgan, then of Princeton, presented evidence on pricing on the Internet, evidence that casts doubt on the law of one price. Stanley Leibowitz of the University of North Texas argued that the New Economy is not so new after all, and took issue with some of the claims regarding the importance of network effects in the New Economy. Finally, Michael Bradley of the George Washington University presented an analysis of a large old-economy industry that appears to exhibit network effects, the postal service, and examines how the New Economy is impacting its future role and even its future survival.

\section{NETWORK INDUSTRIES AND ANTITRUST POLICY}

Nicholas Economides, in 'Competition policy in network industries: An introduction', discusses the importance of network economics in the New Economy, as well as the application of antitrust law and regulatory rules to 
network industries. Some of the relevant features of network industries include network effects, market structure, market share and profits inequality, choice of technical standards, relationship between the number of active firms and social benefits, existence of market power, leveraging of market power in complementary markets, and innovation races. He analyses the application of antitrust laws and antitrust policy in network industries, and finds there are significant differences in the effects of antitrust laws and policies on network and non-network industries.

Economides emphasizes that network industries make up a large part of the economy. His primary examples are telecommunications, including voice and data services, and computer software and hardware. Telecommunications includes the Internet and World Wide Web. These two sectors have been engines of growth for the national and world economy. Other networks that precede the New Economy include airlines, railroads, roads, and shipping, and the delivery services that 'live' on these networks, including the postal service and its competitors.

Economides also discusses virtual networks, collections of compatible goods that share a common technical platform. All computers running Windows 95 can be thought of as a virtual network. Compatible computer software and hardware make up a network, and so do computer operating systems and compatible applications. More generally, networks are comprised of complementary components, so they also encompass wholesale and retail networks, as well as information networks and servers such as telephone Yellow Pages, Yahoo, Google, etc.

Adding to the importance of networks from a public policy point of view is the fact that network industries often provide necessities. Monopolization in such a setting can have significant social and political implications.

There may be a number of anti-competitive concerns in a network industry. The focus of his chapter is the question: Since network industries have special common features, are there special competition policy issues arising out of key features of network industries? If yes, what is the framework of the public policies that can be pursued to address these issues?

Economides reaches the following series of conclusions regarding antitrust intervention in network industries. First, the benchmark case against which to judge the firm is not the perfectly competitive equilibrium but is instead a network industries equilibrium that involves substantial inequality. Second, harming a competitor is not sufficient reason for antitrust action. The important issue should be harm caused to consumers. Third, appropriate caution should be exercised due to uncertainty regarding the evolution of a network industry in the absence of any anti-competitive action. Fourth, it should be recognized that in a network industry monopoly may maximize total surplus. Fifth, and related to the first point, it is not 
possible for the long-term equilibrium to involve equal market shares, and even in the short run such an equilibrium may have low total surplus. Sixth, competition limits the importance of path dependence and the value of the installed base, so that upheavals do occur in network industries. Lock-in can be and is overcome. Economides recommends that antitrust policy adopt these guidelines and recognize that antitrust policy for network industries has different requirements from antitrust policy for other industries.

\section{PRICE DISPERSION}

John Morgan, presented 'Persistent price dispersion in online markets', a paper coauthored with Michael R. Baye and Patrick Scholten. This examined the failure of the 'law of one price' by looking at Internet markets. In response to the observed failure of the law of one price, economists such as George Stigler and Hal Varian have proposed explanations for how dispersed prices can comprise an equilibrium. One approach generates price dispersion because of heterogeneities in costs or service levels, which lead to an equilibrium in which different firms charge different prices for otherwise homogeneous products. An alternative approach generates price dispersion through randomized pricing strategies by firms.

Internet markets provide an ideal setting for examining price dispersion for homogeneous products. Information on pricing by alternative suppliers is easily obtained, including information on shipping costs and taxes. Thus Internet markets provide an almost-ideal environment for testing the law of one price as well as theories explaining equilibrium price dispersion for homogeneous products.

Morgan et al. find that price dispersion is large and persistent even in well-established online retail markets. They collect data on leading price comparison sites on the Internet and find price dispersion for identical consumer electronics products listed by multiple retailers. On average, they find that the highest price for a consumer electronics product is 57 per cent above the lowest available price. They also find that a consumer who simply consults the comparison site to find the lowest price would save about $\$ 31$ relative to a randomly selected supplier.

Morgan et al. report that this price dispersion persists across products and across time. They find no convergence to the 'law of one price', even controlling for differences in shipping charges and inventories. They find various ways to control for advertising, disclosures about shipping costs, consumer service, and a variety of other features and still find that 28 per cent of price dispersion remains unexplained. 


\section{NETWORK ECONOMICS - A DISSENTER}

Stan Liebowitz presented 'Network meltdown: the legacy of bad economics'. This questions whether the New Economy is all that new, and also questions claims that a new economics is needed for study of the New Economy. Liebowitz argues that the Internet, an important component of the New Economy, creates value by reducing the costs of transmitting information, similar to the contribution of the automobile and airplane in reducing the cost of transportation. The reduction in information transmission costs is an important achievement. But, Liebowitz argues, it does not change the laws of economics.

What distinguishes the Internet from prior telecommunication technologies is its ability to quickly retrieve information. Users can quickly find information and retrieve it for current or future uses. But this characteristic of the Internet is not revolutionary in its implications for economics.

Liebowitz points out several changes the Internet may bring to business. It may well reduce the market power conveyed to firms based on geographic location. It may also have an impact on brand name loyalty, although here Liebowitz is uncertain as to the direction of the effect.

Liebowitz specifically addresses some of the features of the Internet that are often touted as being especially important. These include network effects, economies of scale, and the first mover advantage and its related symptom, lock-in. Liebowitz acknowledges that the Internet and companies either existing on the Internet or companies supplying infrastructure for the Internet are in part characterized by some of these features. But, he argues, other firms and other industries that long preceded the New Economy also had these features. Liebowitz presents case studies to support his claims. In the end, he believes that too much is made of the Internet as requiring a new or special economics.

\section{THE POSTAL SERVICE: WHERE THE NEW ECONOMY MEETS THE OLD}

The final paper, presented by Michael Bradley, was 'Should we teach an old economy dog New Economy tricks? The role of a postal service in the New Economy', coauthored with Dennis Jansen. Michael Bradley argues that the US Postal Service provides an excellent case study of an 'old economy' institution that is being affected by the New Economy and by competition from firms and products that are part of the New Economy.

Bradley argues that the postal services industry remains large and critical for the smooth functioning of the economy. The timely, secure and 
reliable delivery of mail communications remains a vital element of the economy's infrastructure. Households and businesses depend on physical mail for delivery of bills, documents, payments, and merchandise. The important public policy issue is how to deal with the effect of the New Economy on postal services. Historically the US government has taken a special interest in guaranteeing the existence of universal postal services, regarding this as a fundamental infrastructure issue. Thus there is a continuing public policy interest in the US Postal Service and the impact of the New Economy on it.

The impact of the New Economy on the US Postal Service has been mixed. While email dominates many interpersonal and business communications, this has come at the expense of telecommunications more than postal services. In fact, Internet shopping has increased demand for package delivery. Further, advances in computing power have dramatically increased the sophistication of direct mailing in targeting selected audiences while at the same time reducing the cost of preparing such mailings, leading to growth in advertising mail. Finally, computerization of mail processing has dramatically increased productivity.

Despite these positives, the major anticipated effect of the New Economy on postal services is negative. This follows from the assumed diversion of volume from the postal mail stream to the electronic message stream. The main concern is bill presentment and bill payment, bulk mail reply mail, and bulk mail documents. About one-third of the US Postal Service's First Class mail stream is made up of bills and statements, and both seem particularly vulnerable to electronic diversion. While the speed with which this diversion takes place is uncertain, most analysts agree that it will happen.

The key question is what impact this diversion will have on the future of postal services, what role they will play in the economy and what response, if any, should be put in place to ensure the best social outcome in light of this change. Bradley begins by constructing a model of a postal service that embodies some of the key aspects that relate to the impact of the New Economy on postal service performance. Solving this model gives a baseline scenario for estimating the effects of electronic diversion from the physical mail stream. This diversion has a number of effects, as the postal service must raise rates to offset lost revenue associated with lost volume. Because demand is inelastic at current prices, this works, at least initially. But marginal costs rise as economies of scale are reversed, and markups increase. Eventually elasticity increases and, at some point, no increase in price generates additional revenue. The postal service is no longer a viable private entity and some policy action would be required.

Various policy actions have been suggested to deal with this situation, including allowing or encouraging the postal service to enter the electronic 
messaging market. This has been prevalent in Canada and in various European countries including Denmark, the UK, and France. Bradley uses his model to study the effect of adopting such a policy, and finds that the postal service can avoid increasing its rate on physical mail to unsustainable levels by entering the electronic messaging market. Even modest revenues earned in the electronic arena could defer the onset of public subsidies to the postal service.

This analysis raises substantial additional policy issues, including issues of cross-subsidization, the advisability of government competing with private firms, and concerns for efficiency of the postal service. However, postal services are likely to continue to be important in the New Economy, so that these issues will require policy-makers to decide on the appropriate reaction to the impact of the New Economy on the postal service.

\section{CONCLUSION}

These eight chapters provide a good overview of the New Economy, including the right amount of skepticism regarding just how new or unique it is. In retrospect, I wish I had included a piece on the stock market in the New Economy, but I think this collection provides an introduction and background that will prove useful to anyone interested in the New Economy, especially policy-makers, analysts, and academics wanting a general overview of it.

The issues raised here are mostly unsettled, and researchers continue to focus on various aspects of the New Economy. In particular, research continues on the productivity increase that marks it, including deeper explanations for the increase in the mid-1990s, and, ideally, better explanations for the decrease in the mid-1970s that persisted for two decades. The debate continues over just how unique is this productivity increase, how it fits into economic history, and how it compares to past experiences with innovation and adoption of new technologies.

Research on the impact of globalization and its effects on the New Economy, and the effects of the New Economy on globalization, also continues. I expect that an important area for future research will be the role of network effects in international economics and in the diffusion of innovations across countries.

The impact of the New Economy on monetary policy-making is perhaps a bit more esoteric, although the declining role of the monetary base and the very real problem of monetary policy-making in the absence of government debt instruments, while not necessarily New Economy topics, may become very important issues in the next decade. 
The role of network effects and the appropriate antitrust policy for network industries is a research area just beginning to flower, encouraged by the Microsoft antitrust case and the efforts of many economists as expert witnesses or interested observers on both sides of the issue. The arguments over just how important are these network effects, and how unique their role is in the New Economy, will continue.

Pricing on the Internet is a fascinating topic for economists, and the results presented in this volume suggest that the law of one price may need to be mentioned with caveats in the future. The idea of equilibrium price dispersion for homogenous products in a market is a theoretical idea that has more empirical support than many might have predicted, and the availability of data from prices posted on the Internet makes for an almost-ideal testing environment.

Finally, the impact of the technological innovations of the New Economy on various old-economy industries such as the postal service will be an area that continues to be of interest to both academics and policymakers. Whether the postal service will survive as currently constituted, with universal service requirements and other restrictions, remains an open question. Indeed, some of the network features that characterize the postal service may make it especially vulnerable to the effects of competition made possible by the new technologies characterizing the New Economy. Policymakers will ultimately face the question of how to handle the problem of the potential demise of the postal service, at least as we know it. 